\title{
Financial performance of air transport companies: an analysis of the non-Pareto-efficient space in data envelopment analysis
}

\author{
E. Fernandes ${ }^{1}$, H. M. Pires ${ }^{2}$, M. P. E. Lins ${ }^{1} \&$ A. C. M. Silva ${ }^{1}$ \\ ${ }^{1}$ COPPE Coordenação de Programas de Pós-Graduação de Engenharia, \\ Federal University of Rio de Janeiro, Brazil \\ ${ }^{2}$ FACC Faculdade de Administração e Ciências Contábeis, \\ Federal University of Rio de Janeiro, Brazil
}

\begin{abstract}
This paper studies the financial performance of public air transport companies. Data envelopment analysis (DEA) is applied to three dimensions: financial variables related to capital structure (financial leverage) as input, and firm size and tangible assets as outputs. A discussion between the classical DEA method of variable return of scale and the Russel efficiency is developed in cases where the decision making unit (DMU) lies in non-Pareto-efficient space. The paper shows the method managers may follow to correct the performance index of the DMU, so they may make better decisions about the path to the efficiency frontier, using both approaches, and considering the minimization of inputs and the maximization of outputs.

Keywords: data envelopment analysis, financial performance, air transport companies.
\end{abstract}

\section{Introduction}

Data envelopment analysis (DEA) is a non-parametric method aimed at measuring the performance of firms, organizations, programs, i.e., the performance of business units under analysis, which are usually called decision making units (DMU). The procedure involves a mathematical technique based on linear programming, which does not need the functional form relating inputs and outputs to be specified. This way, DEA is not proposed to format a 
production function, but to study optimal relationships between inputs and outputs. DEA optimizes each observation with the aim of building an efficiency frontier, which consists of a curve or discrete surface formed only by efficient DMUs, i.e., those that present best practices in relation to the whole set under analysis. Based upon the determined frontier, we found the maximum efficiency benchmarking DMUs of the sample (Figure 1). The efficiency frontier can be obtained by considering two hypotheses: constant scale return (CSR) or variable scale return (VSR). Evidently, one must remember that it is a relative efficiency, since we are working with samples.

Charnes et al. [1] pose that DEA involves an alternate principle for the extraction of information about a group of observations. In contrast with parametric approaches, which are aimed at optimizing a regression plan by means of data analysis, DEA optimizes on each observation, with the aim of calculating a frontier determined by the Pareto-efficient DMUs. This way, DEA allows an efficiency analysis of each DMU and of possible development routes towards the efficiency frontier, i.e., towards the selected benchmarking.

An important element in the formulation of the DEA is the inefficiency level of each variable under analysis, both in relation to the inputs and the outputs. Figure 1 shows a generic configuration where the analysis regions of the DEA that are discussed in this article can be seen, considering the RVE frontier. $R_{1}$ is the Pareto-efficient projection region, $\mathrm{R}_{2}$ is the non-Pareto-efficient projection region for the output approach, $\mathrm{R}_{3}$ is the non-Pareto-efficient region for input and output, and $\mathrm{R}_{4}$ refers to the non-Pareto-efficient region for the input approach. In order to facilitate the graphical representation, Figure 1 presents only one input and one output. However, Charnes et al. [1] demonstrate that the conclusions for this case can be generalized for a varied number of inputs and outputs.

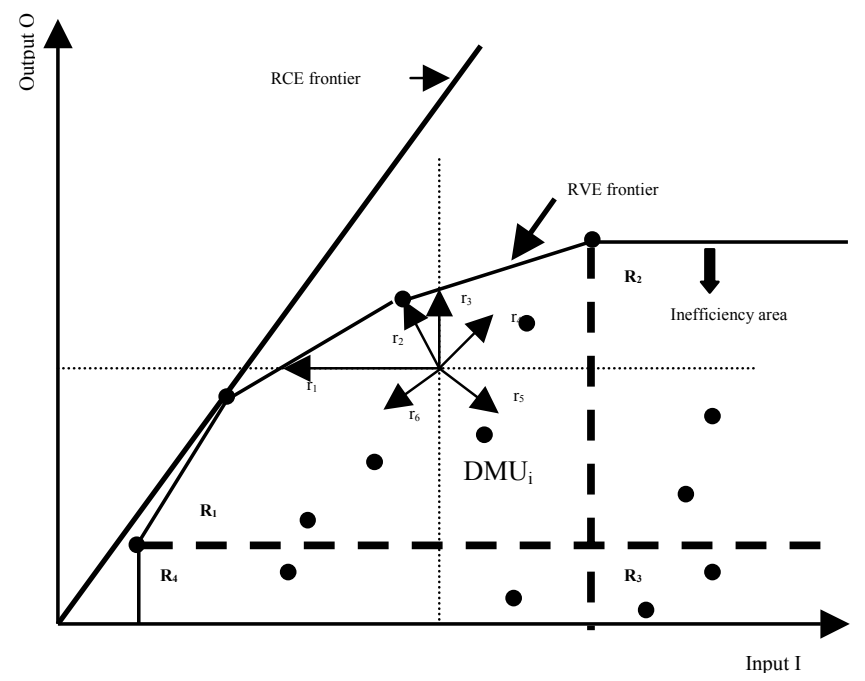

Figure 1: $\quad$ DEA regions. 
The case study developed for this article deepens the analyses carried out by Capobianco and Fernandes [2], and Fernandes and Capobianco [3] for airlines positioned in the non-Pareto-efficient region, using Russel's efficiency approach. Results show that the performance evaluation of the DMUs located in the nonPareto-efficient regions $\left(R_{2}, R_{3}\right.$, and $R_{4}$ in Figure 1$)$ can be distinct from the one calculated by the classical methodology. Such situation can induce the manager to make inadequate decisions for the development of the DMU under analysis.

\section{Russel's analytical methodology}

The existence of slacks, associated to the projection on non-Pareto-efficient regions occurs in practically all case studies. Hence the importance of recurring to methods that admit non-radial projections, such as restrictions to weights (Estellita Lins et al. [4]) and multi-objective models (Estellita Lins et al. [5]. Non-radial models consider that inputs can be reduced in different proportions and that outputs can be increased at different rates, in order to attain a Paretoefficient target at the DEA frontier. The efficiency measure proposed by Russel considers that the value of the performance indicator is given by a ratio between the simple average of the partial efficiencies of the inputs and the simple average of the partial efficiencies of the outputs. The proposed linear programming model has as objective function the minimization of this ratio. The restrictions are similar to the ones related to the classical DEA models, assuring the characteristic of being non-oriented by simultaneously allowing the reduction of inputs and increase of outputs.

In this article, we are proposing the use of Russel's performance indicator formula or SBM (Slacks Based Measurement), proposed by Tone [6], but without necessarily conditioning it to the projected target. The projection will be done by using a non-Archimedean DEA classical model, in order to obtain a Pareto-efficient target, and, in the sequence, we will use the target's coordinates, along with the coordinates of the observed DMU, in order to calculate the efficiency index in an orientation of input. This way, there is no problem in using Russel's non-linear formula, or alternatively, SBM.

\section{Data and financial variables}

With the aim to organize the data in a consistent manner, we used the financial information published by Milne [7,8]. The study involves the analysis of airlines based on their Balance Sheets and Profit and Loss Accounts. This set of data makes it possible to compare the airlines to one another, because it contains the adjustments made with this purpose, and it is both in accordance with the rules of IATA (International Air Transport Association) and worldwide accepted accounting rules (International Accounting Standards Committee). The sample contains data from airlines of different nature, which operate in markets with regulations that allow different kinds of financial strategies. Since it is very difficult to obtain a full adjustment, the study has to be interpreted with due care. 
Considering regular service, public air transport companies, the use of an international database is the only way one can work with this industry. Individual countries have a small number of companies and making tests for each one would possibly result in a greater inaccuracy than for the aggregate sample. The sample contains large regular air transport companies. Another option would be to treat each country separately, including small and non-regular airlines. However, the complexity of the accounting standards, plus the pressures of stock market regarding corporate transparency lead us to consider this selection to be adequate for the purpose of this study. Another problem consists in the necessity to consider both state-owned and private companies. In the case of civil aviation, because it is a strategic industry for countries, the impact of this difference is less significant, because markets are not totally regulated, with government interference even in the case of private companies. Thus, this study considers that these imperfections cannot influence its purposes in a significant manner.

The database is a pooling cross-section time-series with 170 observations of 53 companies from 32 countries, between the years of 1993 and 1997. It was not possible to make observations of all the years for all the companies, mainly because of the changes in the periodicity of financial reports of a given airline (in this case, only data with a constant periodicity of 12 months were accepted), and DEA's limitation of accepting only positive values different from zero. Additionally, there is no reason to use companies with negative profitability or negative net worth in an efficiency analysis. Table 1 presents the total number of companies with data available for each year.

Table 1: $\quad$ Database per year.

\begin{tabular}{|l|r|r|r|r|r|r|}
\hline Years & 1993 & 1994 & 1995 & 1996 & 1997 & Total \\
\hline Number of companies & 25 & 36 & 41 & 34 & 34 & 170 \\
\hline
\end{tabular}

Variables were selected according to capital structure. Being considered a strategic financial decision, the choice of capital structure involves the option of financing a business either through loans (third-party's capital) or through shareholders' capital (own capital). The research in the topic aims to identify which factors influence this decision by means of relationship tests, by using regression and correlation analysis. This paper has selected three variables that have been tested by several authors in the attempt to explain the decision regarding the capital structure of a business. Financial leverage (input) is calculated by dividing the total asset by net worth, and firm size (output) is computed as the logarithm of the net income and tangible assets (output) is the ratio between fixed assets and totals. Even though Capobianco and Fernandes (2004) point out that there is no consensus about the relationship direction of the variables, being it possible to be positive, negative or insignificant, for the objectives of this article it is important that there is a negative relationship between the leverage and the other variables, for the application of the input minimization model used in DEA. 
Financial leverage (FL) is an ample measure and it bears the error of including figures that are used in the transaction of the companies, such as suppliers, wages, taxes to be paid etc., which do not represent current financing. However, the calculation includes short-term debts which, according to Booth et al. [9], are greater in developing countries than in developed ones. Another particularity is the calculation of the index by the book value, and not market value. Naturally, tests involving market values would be of interest, but our limitation regarding this kind of information imposed the use of book value. The diversity of countries in the sample may also not be able to allow the calculation of precise measures. However, Rajan and Zingales [10] have not found meaningful indebtedness differences within the group of the seven most industrialized countries of the world (G7) denominated bank-oriented (Japan, Germany, Italy and France) and the ones denominated market-oriented (United States, United Kingdom and Canada). Booth et al. [9], comparing the level of indebtedness of ten developing countries and the ones belonging to the G7 have found that almost all of the developing countries in the sample have smaller debts than the average of the developed ones, no matter if the average is by book value or market value.

Researches that involve the study of variable "company size" have found opposite results regarding its relation with financial leverage. Ferri and Jones [11] and Rajan and Zingales [10] have found a positive relation for all G7 countries, except for Germany. This result would be explained by the fact that large firms have more access to the several sources of capital, are more diversified, and are less likely to bankrupt. Since the expected bankruptcy costs are low, they allow a greater leverage. Meanwhile, Chung [12] and Titman and Wessels [13] have found a negative relation. The size can be seen as the inverted Proxy for the probability of bankruptcy, which justifies a smaller leverage. This inverse relation will be adopted in this study.

Chung [12] and Thies and Klock [14] have found a positive relationship between tangible assets and financial leverage. The same result was obtained by Rajan and Zingales [10] in their research for all G7 countries, considering the variables by book value or market value. Titman and Wessels [13] have not found any statistical significance in their tests, while Ferri and Jones [11] have found a negative relationship. The existence of tangible assets, at first, represent safety for the creditor, since the assets work as a guarantee in the debt contracts. As we are trying to find the smaller level of financial leverage for the companies, we consider the opposite of this relation - total asset divided by fixed asset (asset). This way, we will be looking for the companies with the smaller number of fixed assets. In the case of aviation, one is supposed to expect that the companies will have large fixed assets, represented mainly by airplanes, as compared to other industries, such as retailers, which do not need a large amount of capital in relation to their whole worth. On the other hand, in aviation it is possible not to immobilize the aircraft by making an operational leasing, with an impact only on the operational costs, and not on the asset. Even if it seems apparently paradoxical, our tests aim at efficiency, and do not include the dependence relationship between the variables. If we consider that we are 
searching for large companies with low debt and less fixed assets, we will hypothetically find large companies, efficient in the use of their fleet, and with a smaller debt.

\section{Case study - Russel's measurement for airlines}

The variable financial leverage was considered as an input, and airline size and asset as outputs. After the implementation of the classical DEA model, the following results were obtained in relation to the number of references of each DMU: airlines at the efficient frontier referred to themselves; the remaining DMUs, with varied degrees of inefficiency, present three references, two references or only one reference. The existence of three references means that a plan was formed and in its edges are the efficient airlines (these airlines are found at R1 in Figure 1), while for two references a line was formed (there is one non-Pareto-efficient dimension), and for one reference, a point (there are two non-Pareto-efficient dimensions).

The companies at the efficient frontier and ten randomly chosen companies outside the frontier were selected to be represented in the Figures.

Figure 2, generated from software IDEAL v.1.3 [15], shows the efficient unities: Malev 95, Continental 96, Lufthansa 97, Federal Express 97, AMR 97, Singapore 95 and Singapore 93, which compose the five Pareto-efficient faces defined by three unities each, and one face defined by Singapore 93 and 95 . Input-oriented projections show that several unities are projected upon nonPareto-efficient parts of the frontier.

Figure 3 shows the efficient airlines and 10 other ones in radial projection.

The projection of the inefficient DMU is done according to its references, and it will serve as a basis for the calculation of its comparative position of efficiency

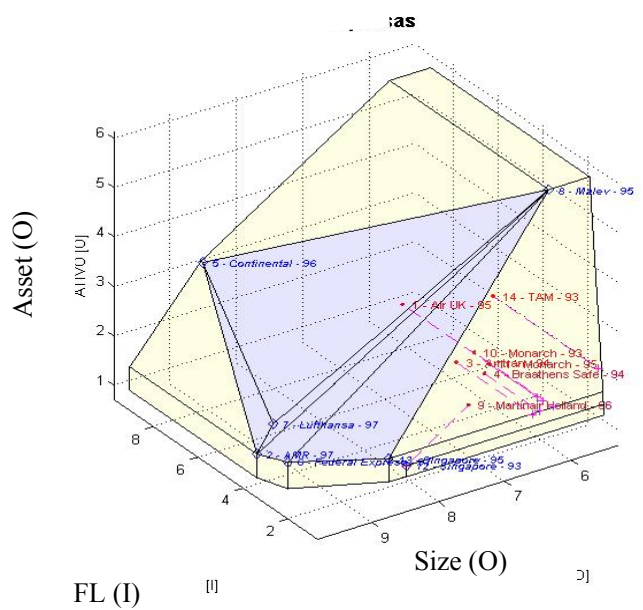

Figure 2: Efficient frontier and other DMUs. 


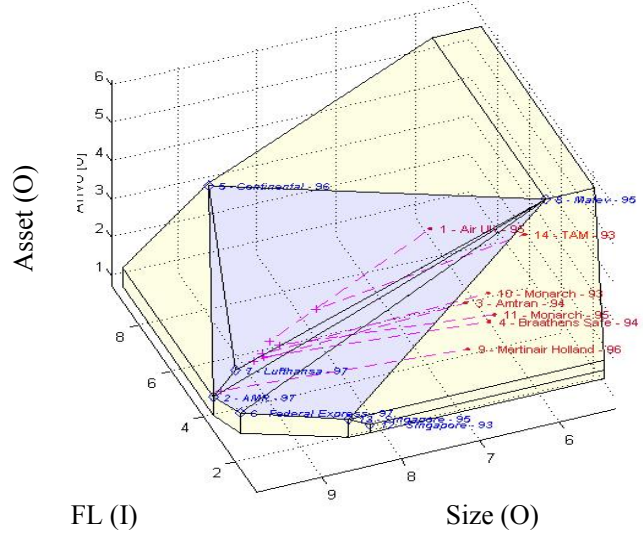

Figure 3: Efficient frontier and DMUs in radial projection.

Table 2: Pareto-efficient target.

\begin{tabular}{|l|r|r|r|r|r|r|}
\hline \multirow{2}{*}{ Airlines } & \multicolumn{3}{|c|}{ Basic data } & \multicolumn{3}{|c|}{ Targets } \\
\cline { 2 - 7 } & $\mathrm{AF}$ & Size & Asset & AF & Size & Asset \\
\hline Air UK 95 & 7,4 & 6,27 & 1,85 & 1,4 & 8,35 & 1,85 \\
\hline Amtran 93 & 3,9 & 6,15 & 1,57 & 1,3 & 8,52 & 1,57 \\
\hline Amtran 94 & 4,7 & 6,36 & 1,55 & 1,3 & 8,51 & 1,55 \\
\hline Braathens Safe 94 & 3,8 & 6,26 & 1,58 & 1,3 & 8,52 & 1,58 \\
\hline Martinair H. 96 & 3,6 & 6,58 & 1,14 & 1,3 & 8,27 & 1,32 \\
\hline Monarch 93 & 4,9 & 6,05 & 1,58 & 1,3 & 8,52 & 1,58 \\
\hline Monarch 94 & 4,3 & 6,17 & 1,63 & 1,4 & 8,49 & 1,63 \\
\hline Monarch 95 & 3,8 & 6,20 & 1,75 & 1,4 & 8,41 & 1,75 \\
\hline TAM 93 & 6,1 & 5,35 & 2,04 & 1,4 & 8,23 & 2,04 \\
\hline TAM 94 & 4,2 & 5,73 & 2,73 & 1,5 & 7,80 & 2,73 \\
\hline
\end{tabular}

in relation to the sample. The value obtained for each DMU by classical efficiency will have to be recalculated through Russel's proposition, since its projection may be positioned outside the Pareto-efficient region.

We used the data of the efficient units shown in Table 2 to calculate the Pareto-efficient targets.

By using the Pareto-efficient target and the original data for the airlines we obtain the partial efficiencies used in the calculation of the Russel's efficiency. Table 3 shows the results and emphasizes the differences between the classical and Russel's efficiencies.

One can notice that only the unities projected on non-Pareto-efficient parts of the frontier suffer an efficiency reduction. In fact, the Russel's measure is identical to the SBM one, used to take into account the slacks that come up because of the Pareto-inefficient projections. Therefore, the use of this measure 
Table 3: Calculation of the difference of results for the airlines' efficiency by the classical model and Russel's efficiency.

\begin{tabular}{|l|r|r|r|}
\hline Airlines & $\begin{array}{r}\text { Classical } \\
\text { efficiency }\end{array}$ & $\begin{array}{r}\text { Russel's } \\
\text { efficiency }\end{array}$ & $\begin{array}{r}\text { Difference } \\
\text { (Classical-Russel) }\end{array}$ \\
\hline Air UK 95 & 0,187 & 0,160 & 0,027 \\
\hline Amtran 93 & 0,349 & 0,293 & 0,057 \\
\hline Amtran 94 & 0,284 & 0,243 & 0,041 \\
\hline Braathens Safe 94 & 0,355 & 0,301 & 0,054 \\
\hline Martinair Holland 96 & 0,371 & 0,308 & 0,063 \\
\hline Monarch 93 & 0,277 & 0,230 & 0,047 \\
\hline Monarch 94 & 0,312 & 0,262 & 0,049 \\
\hline Monarch 95 & 0,365 & 0,310 & 0,055 \\
\hline TAM 93 & 0,231 & 0,182 & 0,049 \\
\hline TAM 94 & 0,359 & 0,304 & 0,055 \\
\hline
\end{tabular}

Table 4: Inefficient companies according to the reference number.

\begin{tabular}{|c|c|c|}
\hline \multirow{2}{*}{$\begin{array}{c}\text { Number of } \\
\text { references }\end{array}$} & \multicolumn{2}{|c|}{ Inefficient companies } \\
\cline { 2 - 3 } & Number & $\%$ \\
\hline 3 & 31 & 19,0 \\
\hline 2 & 112 & 68,7 \\
\hline 1 & 20 & 12,3 \\
\hline Total & 163 & 100,0 \\
\hline
\end{tabular}

provides adjustments for the deviations of the measures resulting from the classical DEA model, due to the existence of slacks.

Besides, this procedure will be applied to the whole set of airlines, providing an appropriate ranking and an analysis of the efficiencies.

\section{Results}

Considering the whole sample of 170 observations, we obtained 7 efficient airlines, representing $4 \%$ of the sample. The remaining airlines are classified as inefficient and are presented in Table 4, according to the number in their reference set.

Considering the companies with three references, no difference was observed between the classical efficiency value and Russel's efficiency value [difference $(\mathrm{C}-\mathrm{R})]$. This way, evidence indicates that when the projection of efficient companies is made on a plan - Pareto-efficient region - it is not necessary to make adjustments. Among the firms with 3 references, $87 \%$ are referred by Fedex 97, Malev 95 and Singapore 95. This provides information on the geometry of the problem. These three DMUs constitute the central face of the frontier at which the companies are projected.

Among the companies with 2 references and 1 reference, in a total of 132, only $1(0,8 \%)$ - All Nippon - has not presented any difference (C-R). The 
greatest difference (C-R) was 19\%, which occurred with ValueJet 94, in which the classic efficiency value was $79 \%$ and Russel's was $60 \%$. Their references were Malev 95 and Singapore 95.

In relation to the classification order of the companies with 3 references, $10 \%$ maintained their position when one considers it by classical efficiency minus the position by Russel's efficiency (position $\mathrm{C}$ - position $\mathrm{R}$ ), while $90 \%$ of this set have presented positive values. This means that they have gained positions, obtaining greater efficiency values by Russel's criterion. This result shows that even though the difference (C-R) is zero, the order is changed by influence of the DMUs which differences C-R are not zero. Even if there were small changes in the values of the efficiency indexes, variations in the positions are not.

All the companies that have one reference are referred by Singapore 93, which has the smaller asset value among the companies that are at the efficiency frontier. These 20 companies (with 1 reference) have an asset that is smaller than Singapore 93's. The use of a single reference reveals a non-Pareto-efficient face, which is a peripheral one, characterized by zero-weights attributed to two variables, which are not considered in the calculation of efficiency by the multipliers model.

\section{Conclusion}

The use of DEA for the performance evaluation of air transport companies has not shown the imprecision that can occur when there is a non-Pareto-efficient situation in the analysis of data. This article discusses, by means of a case study, a methodology for the correction of the relative evaluation of the efficiency of airlines. In this case study, with three dimensions, it was observed that $66 \%$ of the companies with one non-Pareto-efficient dimension and $12 \%$ with two nonPareto-efficiency dimensions. Since DEA is a relative efficiency measure, the changes in the position of the companies suggest that the result of the classical DEA, when the DMU is positioned in a non-Pareto-efficient situation, can lead to mistaken managerial measures because of the reference used. This study shows that whenever one uses DEA analysis for the evaluation of transport companies one must observe whether the benchmarks are of the same number as the dimensions of the formulated problem. If not done this way, one must proceed to a correction process of the calculation by Russel's efficiency methodology, since the classical DEA does not provide an adequate reference to trace the companies' path towards the efficiency frontier.

\section{References}

[1] Charnes, A., Cooper, W. W., Lewin, A. Y. \& Seiford, L. M. (1994) Data Envelopment Analysis: Theory, Methodology and Applications. Kluwer Academic Publishers, Boston.

[2] Capobianco, H. M. P. \& Fernandes, E. (2004) Capital Structure in the World Airline Industry. Transportation Research Part A. Vol. 38, 421434. 
[3] Fernandes, E. \& Capobianco, H. M. P. (2001) Airline Capital Structure and Returns. Journal of Air Transport Management. V. 7, Issue 3, pp. 137-142, may.

[4] Estellita Lins, M. P., Moreira da Silva, A. C. \& Knox Lovell, C.A. (2007) Avoiding infeasibility in DEA models with weight restrictions. European Journal of Operational Research 181, 956-966

[5] Estellita Lins M. P., Angulo-Meza, L. \& Moreira da Silva, A.C. (2004). A multi-objective approach to determine alternative targets in data envelopment analysis. Journal of the Operational Research Society. 55, 1090-1101.

[6] Tone, K. (2001) A Slacks-based Measure of Efficiency in Data Envelopment Analysis. European Journal of Operational Research. 130 (3): 498-509 may 1 .

[7] Milne, I. (1997) Getting Results Airline Financial Profiles. Airline Business, Reed Business Information. Sutton, Surrey, United Kingdom.

[8] Milne, I. (1999) Bridging the Gaap 3, Airline Business, Reed Business Information. Sutton, Surrey, United Kingdom.

[9] Booth, L., Aivazian, V., Demirguc-Kunt, A. \& Maksimovic, V. (2001) Capital Structure in Developing Countries. The Journal of Finance. V. LVI, N ${ }^{\mathrm{O}} 1$, pp. 87-129, February.

[10] Rajan, R. G. \& Zingales, L. (1995) What Do We Know about Capital Structure? Some Evidence from International Data. The Journal of Finance. V. L, N ${ }^{\mathrm{o}} 5$, pp. 1421-1460, December.

[11] Ferri, M. \& Jones, W. (1979) Determinants of Financial Structure: a New Methodological Approach. The Journal of Finance. V. 34, p. 631-644.

[12] Chung, K. (1993) Asset Characteristics and Corporate Debt Policy: an Empirical Test. Journal of Business Finance \& Accounting. V. 20, pp. 8398.

[13] Titman, S. \& Wessels, R. (1988) The Determinants of Capital Structure Choice. Journal of Finance. V. 43, pp. 1-19.

[14] Thies, C. F. \& Klock, M. S. (1992) Determinants of Capital Structure. Review of Financial Economics. pp. 40-52.

[15] IDEAL v1. 3 (2006) Interactive Data Envelopment Analysis Laboratory (2005) Software desenvolvido no Programa de Engenharia de Produção da EE e COPPE/UFRJ. 